University of Nebraska - Lincoln

DigitalCommons@University of Nebraska - Lincoln

Educational Psychology Papers and

Publications

Educational Psychology, Department of

$9-1-2006$

\title{
The Effects of Conjoint Behavioral Consultation in Early Childhood Settings
}

Susan M. Sheridan

University of Nebraska-Lincoln, ssheridan2@unl.edu

Brandy L. Clarke

University of Nebraska-Lincoln, brandy.clarke@unmc.edu

Lisa Knoche

University of Nebraska-Lincoln, Iknoche2@unl.edu

Follow this and additional works at: https://digitalcommons.unl.edu/edpsychpapers

Part of the Educational Psychology Commons

Sheridan, Susan M.; Clarke, Brandy L.; and Knoche, Lisa, "The Effects of Conjoint Behavioral Consultation in Early Childhood Settings" (2006). Educational Psychology Papers and Publications. 26.

https://digitalcommons.unl.edu/edpsychpapers/26

This Article is brought to you for free and open access by the Educational Psychology, Department of at DigitalCommons@University of Nebraska - Lincoln. It has been accepted for inclusion in Educational Psychology Papers and Publications by an authorized administrator of DigitalCommons@University of Nebraska - Lincoln. 


\title{
The Effects of Conjoint Behavioral Consultation in Early Childhood Settings
}

\author{
Susan M. Sheridan, Brandy L. Clarke, and Lisa L. Knoche \\ Nebraska Center for Research \\ on Children, Youth, Families and Schools
}

Carolyn Pope Edwards

Department of Psychology

University of Nebraska-Lincoln

\begin{abstract}
Conjoint behavioral consultation (CBC) is an ecological model of service delivery that brings together parents and educators to collaboratively address shared concerns for a child. This study provides exploratory data investigating the effects of CBC on home and school concerns for 48 children aged 6 and younger. Single-subject methods were used to evaluate the effects of $\mathrm{CBC}$ on individual children. Effect sizes across cases yielded large median effect sizes ( 0.97 at home and 1.06 at school). Results of paired sample $t$ tests suggested significant improvements in parents' perceptions of communication with their child's teacher and in the overall parent-teacher relationship. In addition, parents and teachers reported high levels of acceptability of CBC and satisfaction with the consultant. Implications and limitations of the study and future research needs are presented.
\end{abstract}

The influence of a child's early educational experiences on the trajectory of his or her educational career has been well established (Alexander \& Entwisle, 1988; Entwisle, Alexander, Cadigan, \& Pallas, 1986; Husen, 1969; Ladd \& Price, 1987; Reynolds, 1991). Parents are children's first teachers, and the essential role of parents in promoting learning is unequivocal (Henderson \& Mapp, 2002). Parents' valuation of education and provision of a literacy-rich home environment, and high-quality relationships between parents and preschool teachers, have been shown to be positively related to young children's academic performance (Brad-

Correspondence should be addressed to Susan M. Sheridan, University of Nebraska-Lincoln, 216 Mabel Lee Hall, Lincoln, NE 68588-0235. E-mail: ssheridan2@unl.edu 
ley, Caldwell, \& Rock, 1988; Hill, 2001). Indeed, parents' expectations for, and involvement with, school-related activities starts early and affects children's school performance throughout their academic career.

Research findings consistently point to the importance of collaboration among family and school systems for promoting students' academic, behavioral, and social well-being. There is converging evidence that parental participation and cooperation in elementary school is related to increased student achievement, improved school attendance, stronger self-regulatory skills, better study habits, fewer discipline problems, more positive attitudes toward school, more regular homework habits and work orientation, and higher educational aspirations (Epstein, 2001; Grolnick \& Slowiaczek, 1994; Haynes, Comer, \& Hamilton-Lee, 1989; Lee, 1993; Masten \& Coatsworth, 1998; Reynolds, Weissberg, \& Kasprow, 1992; Siu-Chu \& Willms, 1996; Stevenson \& Baker, 1987; Zellman \& Waterman, 1998). The benefits to students are evident even after students' abilities and socioeconomic status are taken into account.

Beyond the active involvement of parents in their child's schooling, continuity among home and school has been found to be important for maximizing academic outcomes (e.g., Conoley, 1987; Hansen, 1986). Continuity among homes and schools is associated with improvements in academic achievement (Hill, 2001), and children's elementary school grades have been shown to decline as a function of increased discontinuity in the interactions between home and school (Hansen, 1986). Furthermore, students who experience discontinuity across their home, school, and peer worlds are at significant risk for mental health concerns (Phelan, Davidson, \& Yu, 1998). Methods for increasing continuity include increasing opportunities for frequent and meaningful dialogue, engaging in shared goal setting and decision making, and delivering coordinated and consistent messages related to learning across home and school (Christenson \& Sheridan, 2001).

Ecological systems theory (Bronfenbrenner, 1977) recognizes the multiple systems contributing to a child's development and the interrelationships among them. Intervention efforts within this framework extend beyond a child or parent focus to the construction of positive relationships among systems. Operationally, this may involve establishing a shared mission, open communication, mutual respect, and co-equal collaboration among all systems on behalf of a child (Pianta, Kraft-Sayre, Rimm-Kaufman, Gercke, \& Higgins, 2001). Continuity among caregiving systems (e.g., family and school), involvement of key stakeholders, and positive relationships among parents and service providers (e.g., early childhood educators) contribute to the effectiveness of early intervention efforts (Rimm-Kaufman \& Pianta, 2000).

Collaboration among key stakeholders that cooperate within a child's life is important for early learning and smooth transitions across systems (Early, Pianta, Taylor, \& Cox, 2001; Eayrs \& Jones, 1992; Ramey, 1999). We view collaborative relationships between home and school as partnerships defined by mutual respect 
and responsibilities, unique and complementary roles, and shared goals and decision making on behalf of a child's learning and development. The goal of collaborative partnerships is "not merely to get families involved, but rather to connect important contexts for strengthening children's learning and development" (Christenson \& Sheridan, 2001, p. 7).

Although collaborative home-school relationships are important at all stages of a child's formal educational experience, this may be particularly true during the preschool and early elementary years (Rafaelle \& Knoff, 1999). The curriculum of the home (e.g., access to learning materials, language stimulation, parental responsivity; Walberg, 1984) during the preschool years has lasting effects on cognitive development throughout early childhood and the primary grades (Bradley et al., 1988). During this time, parents are developing constructs of their role in their child's education, and children are beginning to develop skills and basic schemas about themselves as learners. Thus, parental recognition of the essential role they play in their child's education is vital (Hoover-Dempsey \& Sandler, 1997). Early collaborative experiences between parents and school personnel can support the development of a meaningful role construct and promote future parental involvement and higher student achievement.

Positive relationships and collaborative partnerships among parents and educators are considered primary protective factors (Christenson \& Sheridan, 2001; Weissberg \& Greenberg, 1998) or safety nets (Christenson, 2000) for children. Many strategies have been implemented to improve parent involvement and partnerships. Conjoint behavioral consultation (CBC; Sheridan, Kratochwill, \& Bergan, 1996) is a strategy based in school psychology for embedding specific parent-teacher-consultant collaborations around a child's individual functioning within ongoing teacher practice as a way of strengthening home-school relationships (Sheridan, Warnes, Schemm, Cowan \& Clarke, 2004). CBC is a structured consultation model wherein a consultant works collaboratively with parents, teachers, and support staff to address the academic, behavioral, and social concerns of a child for whom all parties bear some responsibility (Sheridan \& Kratochwill, 1992). This model focuses on the interactions between the child and the primary systems in her or his life, thus strengthening relationships across home and school through joint goal setting and decision making.

A primary goal of CBC is to address the primary concerns a parent and teacher or early childhood professional share for a child. This is attained by (a) identifying and defining a primary need (e.g., social skill development), (b) establishing mutual goals related to the need (e.g., engage in positive interactions with peers), (c) co-constructing a plan that can be implemented across home and preschool or child care center contexts (e.g., modeling, supportive peer play), (d) implementing unique aspects of the plan across settings (e.g., skill training at school, guided play opportunities at home), (e) collecting and using data to determine goal attainment (e.g., frequency and duration of positive play situations with peers), and (f) recy- 
cling through the problem-solving stages as necessary to address current and additional needs (i.e., reassessing the conditions related to social behaviors). Other central CBC goals address the ongoing skill development on the part of all parties (child, parent, teacher) and the strengthening of partnerships among family members and school or center personnel.

CBC embraces an approach to early childhood that includes both child and caregiver foci. Beyond attention to the child in isolation, $\mathrm{CBC}$ directly addresses important principles consistent with an ecological-systems conceptualization of early intervention. These include (a) addressing the priorities and concerns of all primary caregivers, (b) strengthening social supports and promoting partnerships and collaboration among systems, and (c) developing and enhancing the competencies and skills of parents and teachers (Dunst \& Trivette, 1987; Dunst, Trivette, $\&$ Deal, 1994; Sheridan et al., 1996; Sheridan, Warnes, et al., 2004). A CBC consultant supports family members and early childhood educators in determining the focus for services; utilizes existing strengths and resources in intervention planning and design; establishes and strengthens home-school partnerships through communication and collaboration; and enhances families' and teachers' structured problem-solving competencies.

A structured, 4-stage process (i.e., problem/needs identification, problem/ needs analysis, plan development, and plan evaluation; Sheridan et al., 1996) is used in CBC to ensure an organized, comprehensive, data-based approach to joint decision making and problem solving. Three of these four stages are operationalized through a structured interview format (Sheridan et al., 1996). Generally, a school psychology consultant works with a parent and teacher to facilitate the process and guide the discussion. The consultant helps parents and teachers to work together and clarify general concerns into (a) specific needs, goals, and priorities; (b) appropriate data collection procedures; (c) practical and effective intervention procedures; and (d) plans for evaluation, maintenance, generalization, and follow-up. Concomitantly, interpersonal and relationship-building skills are used by the consultant to facilitate open communication, shared decision making, perspective taking, and mutual responsibility among family members and early childhood educators.

Extensive research highlights CBC's success with academic, social, and behavioral issues. Many studies have yielded promising results for various samples and target behaviors (cf. Colton \& Sheridan, 1998; Galloway \& Sheridan, 1994; Sheridan, Kratochwill, \& Elliott, 1990; Weiner, Sheridan, \& Jenson, 1998). For example, results of a 4-year study conducted by Sheridan, Eagle, Cowan, and Mickelson (2001) found meaningful effect sizes for various academic, socioemotional, and behavioral concerns among elementary students, including reading accuracy and fluency, inattention, social skills, anxiety, noncompliance, and disruptive behavior. The results of a regression analysis suggested that the model was likely to be very effective for elementary-school-age children with complex target 
concerns. However, its effectiveness for promoting learning, behavior, and socioemotional development specifically in early childhood populations has not been investigated systematically.

In addition to enhancing child skills, active involvement of (and relationships between) parents and educators is central to the conceptualization of CBC as an ecological approach. Parents and teachers participate jointly throughout the entire process of decision making. However, the degree to which CBC effectively builds partnerships and strengthens parent-educator relationships in early childhood settings is unknown. Likewise, evaluating the extent to which the process addresses the needs of the family and their satisfaction with services is critical (Eayrs \& Jones, 1992). Although the acceptability of CBC for parents and teachers of school-age children is well documented (Freer \& Watson, 1999; Sheridan \& Steck, 1995), perceptions of early childhood professionals have not been explored.

The purpose of this exploratory study was to assess the effects of CBC as a form of early intervention for young children. Characteristics of the child and the parent-teacher relationship were considered. The research questions explored were: (a) the effect of $\mathrm{CBC}$ on learning, behavior, and socioemotional goals across home and school; (b) the effect of CBC on parents' and teachers' perceptions about their relationship with one another; (c) parents' and teachers' perceptions of the effectiveness and acceptability of the CBC process; and (d) parents' and teachers' satisfaction with $\mathrm{CBC}$ consultants and consultation services.

\section{METHODS}

This study was part of a larger project that evaluated the effects of $\mathrm{CBC}$ in natural classroom and home environments over 10 years and two geographic regions (i.e., the intermountain west and Midwest). ${ }^{1}$ Institutional approval to conduct the research with human participants was granted to Susan M. Sheridan. Cases represented here are those where the child was age 6 or younger whose parents or teachers expressed concern with his or her learning, behavior, or socioemotional functioning. The purpose of this study was to investigate effects on individual

\footnotetext{
${ }^{1}$ This study was part of a larger project based on several federal grants for personnel preparation awarded to Susan M. Sheridan, and a research grant awarded to Susan M. Sheridan and Carolyn Pope Edwards. Personnel preparation grants were funded by the U.S. Department of Education, Office of Special Education Programs, and involved mastery-level training of school psychology graduate students in CBC service delivery. The sample included herein was a subset of the entire sample and included only children aged 6 and younger. In addition, a research study funded jointly by the National Institute of Child Health and Human Development; the Office of Special Education Programs; and the Administration for Children, Youth, and Families involved CBC as one component of a larger comprehensive intervention aimed at engaging parents in practices to enhance school readiness among their children.
} 
cases in an exploratory manner. Systematic, rigorous experimental trials were not conducted. Rather, several small- $n$ experimental or quasi-experimental designs (e.g., AB with follow-up, reversal, multiple baseline) were conducted in naturalistic settings, incorporating authentic conditions related to home and school contexts (e.g., parents and teachers served as treatment agents, intervention strategies fit naturally into the environment, outcome and acceptability data were provided by consumers). Given the quasi-experimental nature of this research, findings are considered exploratory in nature.

\section{Participants}

Participants in the study were 50 students, their parents $(n=59)$, and their teachers $(n=44)$. Also involved were 24 graduate student consultants. In several cases, multiple target behaviors were identified and addressed. Therefore, the total number of valid effect sizes was 75. Demographic information for teachers and parents was obtained via self-report questionnaires prior to the onset of each consultation case. Demographic information for children was obtained through parent report.

Child participants. Participants were 50 children aged 6 years and younger attending preschool or kindergarten. The mean age of the client was 4.9 years (range $=3-6$ ). In all, $70 \%$ of the child participants were male, and $30 \%$ were female. Of the participating children, $66 \%$ were enrolled in a public school (e.g., kindergarten) program, $32 \%$ were in Head Start, and $2 \%$ were in private preschools. We found that $21 \%$ of the students lived in single-parent households, and $15 \%$ were considered to be of low socioeconomic status, with an annual household income of less than $\$ 15,000$. Of the child clients, $74 \%$ were White; $8 \%$ were biracial; $6 \%$ were Hispanic; $6 \%$ were African American; and the remaining 6\% were Arabic, Vietnamese, or Chinese. English was the primary language spoken in the home for $87 \%$ of the child clients.

Parent participants. Each child client had at least one parent or guardian that participated in the $\mathrm{CBC}$ process. Of the 59 parent participants, $81 \%$ were mothers, and $19 \%$ were fathers. In $23 \%$ of cases, both parents participated in at least some of the consultation meetings. Of the participating parents, $81 \%$ were White, and 19\% were non-White (Hispanic, African American, Arabic, Vietnamese, Chinese). The average age of the parent participant was 33.5 years. We found that $4 \%$ had not graduated from high school, $73 \%$ had a high school diploma as their highest degree, $16 \%$ had a bachelor's degree, and 7\% had an advanced (master's, doctoral, or medical) degree. Although demographic data were available for most parents, in the majority of cases perceptions of outcomes (i.e., social validity data) and parent-teacher relationship data were collected from only one parent. In these cases, the parent who consistently attended CBC meetings (in most cases, mothers) completed the final data collection forms. 
Teacher participants. In all, 44 teachers participated in the study. Of those teachers, $77 \%$ indicated they had no previous involvement with CBC, whereas $23 \%$ reported prior experiences with the process. In all, $89 \%$ of the teachers were female, and $11 \%$ were male. The mean age was 38.6 years. All teacher participants were of European American descent. Of the teachers, 57\% taught in regular education (i.e., kindergarten or first grade) classrooms, 34\% in preschools (including Head Start), $7 \%$ in early childhood special education classrooms, and the remaining $2 \%$ were assistant teachers. We found that $9 \%$ of the teachers had an associate's degree, $61 \%$ had a bachelor's degree, $28 \%$ had a master's degree, and $2 \%$ had a doctorate.

Consultants. Consultants in the study were 24 trained graduate students in one of two accredited school psychology programs in the Midwest or intermountain west. The students demonstrated mastery of CBC procedures in the context of a highly structured criterion-based consultation training program (including didactic coursework, extensive readings and discussion, role plays with confederate consultees coded for completion of $\mathrm{CBC}$ objectives, individualized performance feedback, and videotaped evaluation). Mastery was defined as demonstration of at least $85 \%$ of the objectives on each of the CBC interviews across at least three analogue role plays. At the time of the study, 52\% of the consultants had had previous experience with the $\mathrm{CBC}$ model. The mean age of the consultants was 28.4 years. In all, $83 \%$ were female, and $17 \%$ were male. Of the participating consultants, $92 \%$ were White, and $8 \%$ were Hispanic.

\section{Setting}

Consultation cases were conducted across several locations (i.e., public school, Head Start center, private preschool) in large midwestern and western cities. Consultation interviews were held primarily in teachers' classrooms. Interventions were implemented in the classrooms and homes.

\section{Dependent Variables}

Behavioral outcomes, evaluated through direct observations of target concerns, served as one dependent variable. Observations were conducted by parents and teachers in naturalistic settings. The second dependent variable was parents' and teachers' perceptions of their relationship. The perceived quality of the parent-teacher relationship was measured by a self-report instrument administered prior to and on completion of CBC procedures.

Behavioral outcomes. Observations of student performance were used to assess the effects of CBC. Specific target behaviors (e.g., noncompliance, tan- 
trumming) were identified and operationally defined for each student. Parents, teachers, and consultants developed data collection procedures that were specific to each consultation case and appropriate to the specific context of the intervention. Permanent products (e.g., charts on which each instance of a behavior yielded a mark or tally) were yielded for $18 \%$ of the behavioral data. For the remaining $82 \%$ of behavioral data, parents and teachers were given instructions on the use of standardized behavioral records, and periodic random observations of children's target behaviors were conducted by consultants to ensure reliability in data recording. Data were provided across consultation stages and experimental phases (i.e., baseline, treatment, and follow-up). In many cases, more than one target behavior was identified and became the focus of consultation interventions. Effect sizes were computed for each target behavior and thus served as the unit of analysis.

Quality of parent-teacher relationship. The Parent-Teacher Relationship Scale-II (PTRS; Vickers \& Minke, 1995) was used to assess parents' and teachers' perceptions regarding the quality of their relationship. The Likert-type scale contains 35 items scored on a 5-point scale ranging from 1 (poor) to 5 (excellent). Factor analysis of the PTRS yielded two factors. Factor I, labeled Joining, contains items related to cohesion or feelings of interpersonal connectedness between teachers and parents. The Joining factor also incorporates items related to adaptability. Specific components loaded on Factor I include (a) a sense of affiliation and support, (b) availability and dependability of both parents and teachers, (c) shared beliefs/expectations regarding the child and each other, and (d) adaptability of both parties. Cronbach's alpha coefficients for the Joining factor are .98 for both the parent and teacher scales. Factor II, labeled Communication to Others, includes items designed to measure sharing of information and emotions. For the Communication scale, Cronbach's alphas are .86 and .85 for parents and teachers, respectively (Vickers \& Minke, 1995). Parents and teachers completed the scale at the onset and on completion of the $\mathrm{CBC}$ problem-solving process.

\section{Social Validity}

Subjective measures were used to evaluate the social validity, or clinical meaningfulness, of the consultation process. Specifically, subjective assessments of outcomes, perceptions of goal attainment, and ratings of acceptability and satisfaction of the CBC consultant and services were collected.

Perceptions of outcome. Parents' and teachers' perceptions of case outcomes served as one form of social validity measure and were assessed with the revised version of the Behavior Intervention Rating Scale (BIRS; Von Brock \& Elliott, 1987). The BIRS contains 24 items rated on a 6-point Likert-type scale. Factor analysis of the BIRS yielded three factors: Acceptability, Effectiveness, and 
Time to Effect (Elliott \& Von Brock Treuting, 1991). A study conducted by Von Brock and Elliott (1987) reported alpha coefficients of .97 for the total scale and $.97, .92$, and .87 for the Acceptability, Effectiveness, and Time to Effect factors, respectively. Internal consistency of the BIRS total scale revised for CBC is .95 for teachers and .93 for parents (Sheridan et al., 2001).

The Effectiveness factor on the BIRS contains 7 items scored on a 6-point Likert-type scale ranging from 1 (low perceived efficacy) to 6 (high perceived efficacy). Minor modifications to the original BIRS were made to increase its applicability with CBC procedures, and its psychometric properties were maintained (Freer \& Watson, 1999; Sheridan \& Steck, 1995). Alpha coefficients for the Effectiveness factor for a CBC sample are .95 for both parents and teachers (Sheridan et al., 2001).

Goal attainment. Goal Attainment Scaling (GAS; Kiresuk, Smith, \& Cardillo, 1994), the second social validity measure, was used to evaluate participants' perceptions regarding the attainment of consultation goals. On completion of the final $\mathrm{CBC}$ interview, parents and teachers reported the degree to which the student met his or her goal through the use of a 5-point Likert-type scale ranging from -2 (situation got significantly worse) to +2 (goal completely met). Scores on the GAS were recalibrated to a 5-point Likert-type scale for analysis, ranging from 1 (situation got worse) to 5 (goal completely met). Reviews of the reliability and validity of the GAS indicated interrater reliability indices between $r=.87$ (Kaplan \& Smith, 1977) and $r=.93$ (Schippits \& Baxter, 1978, as cited in Cardillo \& Smith, 1994). Test-retest reliability yielded correlations of $r=.84$ over a 2- to 3-week period (Woodward, Santa-Barbara, Levin, \& Epstein, 1978). In addition, adequate construct (e.g., Johnson \& Greenberg, 1985) and criterion-related validity (Jacobs \& Cytrynbaum, 1977) have been reported.

Acceptability ratings. The BIRS Acceptability factor was used to assess a third form of social validity, parents' and teachers' acceptability of the CBC problem-solving process. This scale comprises 15 items scored on a 6-point Likert-type scale ranging from 1 (not at all acceptable) to 6 (highly acceptable). A previous study investigated the reliability of the BIRS adapted for CBC and yielded alpha coefficients of .94 and .86 for parents and teachers, respectively (Sheridan et al., 2001). For a review of the reliability and validity of the original BIRS scale, see Elliott and Von Brock Treuting (1991).

Satisfaction. The final social validity measure assessed consumer satisfaction with the CBC consultant and services. Parents' and teachers' satisfaction was measured using the Consultant Evaluation Form (CEF; Erchul, 1987). The CEF comprises 12 items. Items are scored on a 7-point Likert-type scale that evaluates the degree to which the consultant was perceived as helpful. Consultees completed 
the scale following the final CBC interview. Early research yielded satisfactory internal consistency estimates $(\alpha=.95$; Erchul, 1987). Alpha coefficients of .83 for parents and .89 for teachers were found for a large CBC sample (Sheridan et al., 2001).

\section{PROCEDURES}

\section{Consultant Training in CBC}

School psychology graduate students, trained to mastery in CBC procedures and objectives, served as consultants. Central to the consultants' training was enrollment in an advanced seminar and practicum course. The practicum used a competency-based training model, in which consultants were required to attain $85 \%$ mastery of CBC objectives prior to completing field cases. On achieving mastery, consultants were placed in local elementary schools or Head Start classrooms. Within school placements, consultants were responsible for creating partnerships and providing consultation services to parents and teachers. This was accomplished by frequent phone calls to maintain contact and assess the need for assistance or support, and in some cases home visits and notes home.

For the purposes of supervision and evaluation, all consultation interviews were audiotaped. Following each interview, consultants received supervision from an advanced graduate student and/or course instructor previously trained and experienced in CBC. Additional information on the CBC supervision model is available in Sheridan, Salmon, Kratochwill, and Carrington Rotto (1992).

\section{CBC Procedures}

Referrals for $\mathrm{CBC}$ were received through classroom teachers, special education coordinators, and parents. Upon referral, consultants explained the CBC process to parents and teachers, obtained verbal consent from interested parties, and scheduled a preconsultation interview. The purpose of the preconsultation interview was to establish a working relationship with parents and teachers, discuss procedural details of the interviews, outline the respective roles for parents and teachers, and begin to identify strengths and areas of need for the student. In addition, demographic questionnaires were distributed to parents and teachers and written consent was obtained. Preconsultation meetings were followed by a series of structured CBC interviews.

Problem identification. During the Conjoint Problem Identification Interview, target concerns were collaboratively identified and prioritized in behavioral terms. Table 1 presents the target behaviors identified for home and school and 
TABLE 1

Target Behaviors Identified at Home and School

\begin{tabular}{|c|c|c|c|c|}
\hline \multirow[b]{2}{*}{ Behavior } & \multicolumn{2}{|c|}{ Home Target Behaviors } & \multicolumn{2}{|c|}{ School Target Behaviors } \\
\hline & Frequency & $\%$ & Frequency & $\%$ \\
\hline Noncompliance & 18 & 47 & 22 & 40 \\
\hline Tantruming & 4 & 11 & 4 & 7 \\
\hline Work completion & 4 & 11 & 4 & 7 \\
\hline Off task & 3 & 8 & 8 & 15 \\
\hline Peer interactions & 2 & 5 & 4 & 7 \\
\hline Talking out & 2 & 5 & 3 & 5 \\
\hline Reading skills & 2 & 5 & 4 & 7 \\
\hline Anxiety & 1 & 3 & 2 & 4 \\
\hline Math skills & 1 & 3 & 1 & 2 \\
\hline Encopresis & 1 & 3 & 0 & - \\
\hline Aggression & 0 & 一 & 2 & 4 \\
\hline Language skills & 0 & - & 1 & 2 \\
\hline Total & 38 & & 55 & \\
\hline
\end{tabular}

their frequency across participants. A total of 38 target behaviors were selected by families to address at home, and 55 were identified by teachers to address at school. ${ }^{2}$ In some cases, behaviors were targeted in one setting only (e.g., school), and, in some, more than one target behavior was identified within a setting. Of the target concerns identified at school, $73 \%$ were behavioral, $20 \%$ were academic, and $7 \%$ were social. At home, $74 \%$ of the concerns were behavioral, $17 \%$ were academic, and $9 \%$ were social.

A preliminary functional assessment was conducted to explore ecological factors affecting the target behavior. Data collection procedures were also discussed. Specifically, parents, teachers, and the consultant discussed methods by which parents and teachers could easily and readily monitor and record behavioral data related to the target concerns. In most cases, frequency or interval procedures were used to track behaviors. Examples include using a golf stroke counter for teachers to count behaviors and a swatch of masking tape secured to their wrist for parents to mark the frequency of a behavior while in public. Behavior record forms, or charts used for easy and reliable data collection, were provided to parents and teachers. Specifically, data collection forms were provided to parents and teachers to (a) standardize the observational procedures, (b) enhance training in data collection procedures, (c) increase reliability of data collection, and (d) provide a permanent record of student performance (Noell, in press). To prepare parents and teachers for the task of data collection, consultants reviewed the specific procedures in

\footnotetext{
${ }^{2}$ Effect sizes are not available for all target behaviors; thus, the number of behaviors targeted is not equal to the number of effect sizes used in the analyses.
} 
detail, checked for understanding, monitored use of forms throughout $\mathrm{CBC}$, and debriefed with parents and teachers regarding their data collection practices and challenges to ensure that parents and teachers were able to implement specific data collection techniques.

Problem analysis. During the Conjoint Problem Analysis Interview, baseline data were evaluated to determine if they represented an accurate representation of the concern. Baseline data were used to establish the goal or desired level of performance for the child. Parents and teachers were guided through re-exploration of the conditions surrounding the concern and then hypothesized the function of the behavior. Using information gathered in the functional assessment, parents and teachers collaboratively developed an intervention plan, with intervention steps clearly defined and roles and responsibilities identified. Intervention components were summarized on a treatment plan worksheet, written by the consultant in conjunction with parents and teachers. Data collection procedures were reaffirmed at the end of the interview.

Intervention development and implementation. Interventions were implemented across settings in the treatment plan implementation stage. Table 2 presents the frequency of interventions used to address concerns across settings. Across cases, 13 different intervention types were implemented at school, and 12 different interventions were implemented at home. It was common for several in-

TABLE 2

Interventions Implemented at Home and School

\begin{tabular}{|c|c|c|c|c|}
\hline \multirow[b]{2}{*}{ Intervention } & \multicolumn{2}{|c|}{ Home Interventions } & \multicolumn{2}{|c|}{ School Interventions } \\
\hline & Frequency & $\%$ & Frequency & $\%$ \\
\hline Positive reinforcement & 23 & 29 & 28 & 24 \\
\hline Praise & 14 & 18 & 21 & 18 \\
\hline Parent or teacher training & 10 & 13 & 11 & 9 \\
\hline Create schedule & 7 & 9 & 5 & 4 \\
\hline Home note & 5 & 6 & 10 & 8 \\
\hline Prompts & 4 & 5 & 14 & 12 \\
\hline Self-monitoring & 4 & 5 & 7 & 6 \\
\hline Social skills training & 4 & 5 & 5 & 4 \\
\hline Parent or teacher tutoring & 3 & 4 & 5 & 4 \\
\hline Time out & 3 & 4 & 3 & 3 \\
\hline Redirection & 2 & 3 & 0 & - \\
\hline Token system & 1 & 1 & 7 & 6 \\
\hline Classroom management & 0 & - & 2 & 2 \\
\hline Full cleanliness training & 0 & - & 1 & 1 \\
\hline Total & 80 & & 119 & \\
\hline
\end{tabular}


tervention techniques to be used within one case. Across both settings, positive procedures (i.e., reinforcement and praise) were used most frequently (i.e., $47 \%$ at home and $42 \%$ at school) to strengthen desired behaviors. Consultants continuously monitored implementation of the plan through frequent contact with parents and teachers to provide support and ensure that they had the necessary skills to implement the plan.

Treatment evaluation. During the Conjoint Treatment Evaluation Interview, data were examined to determine if the consultation goal was met. If the consultation goal was attained, procedures for generalization were discussed. If the goal was not met, plan modifications were made. On termination of the Conjoint Treatment Evaluation Interview, final perception checklists were provided to parents and teachers (Sheridan \& Erchul, 1995). Information related to the referral process and frequency of meetings was collected on the checklist. Several outcome measures assessing consumer satisfaction, acceptability, and goal attainment were reproduced on the forms. Measures included the CEF (Erchul, 1987), the BIRS (Von Brock \& Elliott, 1987), and GAS (Kiresuk et al., 1994). Postage-paid envelopes addressed to the primary investigator were distributed to the parents and teachers for return of the checklists.

\section{Integrity of CBC Process}

Trained observers coded $41 \%$ of available interviews. Individuals who previously completed training in $\mathrm{CBC}$ procedures and who met criteria for mastery of CBC objectives served as coders. Coders listened to audiotapes and completed a CBC objectives checklist to determine which steps were successfully implemented in each interview and to ensure fidelity. The checklists summarized the goals outlined for each CBC interview and were modified from the behavioral consultation objectives checklists used in previous research (Kratochwill, Sheridan, Carrington Rotto, \& Salmon, 1992; Sheridan, 1992). These coding procedures revealed that consultants met $84.4 \%$ of interview objectives for Conjoint Problem Identification Interviews. They met $84.5 \%$ of objectives for Conjoint Problem Analysis Interviews and $94 \%$ of the objectives for the Conjoint Treatment Evaluation Interviews.

\section{Integrity of Interventions}

Treatment integrity of consultation-derived interventions across home and school was determined in one of two ways. First, evidence of treatment integrity was determined by reviewing aspects of behavioral programs that yielded permanent products (e.g., sticker charts, contracts, home notes, self-monitoring sheets; Noell, in press). Second, intervention plans were recorded on treatment plan worksheets. The worksheets provided a detailed description of the intervention, including the 
specific steps of the plan, and consultees self-recorded completion of the steps of the treatment plan. Consultants reviewed these worksheets and discussed them with consultees. Intervention fidelity was considered present whenever parents and teachers reported completion of the plan components. These procedures for ensuring treatment integrity are considered liberal; however, they provided a global representation of parents' and teachers' adherence to the plan (Gresham, 1989).

\section{Coding of Data}

Information obtained through demographic questionnaires, behavioral records (i.e., target behaviors, observational data), treatment plan worksheets (i.e., interventions delivered), and final perception forms (i.e., social validity data) were entered into a database by advanced graduate students trained in CBC by the principal investigator. Frequent checks were conducted to verify the accuracy of the data set. Two observers (i.e., graduate students in school psychology) were trained by an advanced doctoral student in data entry and organization. To assess interrater reliability, the observers checked $33 \%$ of the data set. Specifically, for $33 \%$ of the cases, a second observer entered identical data. Interrater reliability was computed by number of cells in the database for which observers agreed, divided by the number of cells for which they agreed plus disagreed, multiplied by 100 . Interrater reliability between the observers was $98.4 \%$, suggesting high levels of accuracy in the database.

\section{Data Analysis}

The effectiveness of treatment plans implemented within the context of CBC was evaluated through single-subject designs. Due to individual differences across cases and settings, various forms of designs were employed. The majority of cases represent an $\mathrm{AB}$ with follow-up design, whereas a small percentage of cases utilized a reversal or multiple-baseline design. Effect sizes were computed for all target behaviors using a "no assumptions" approach (Busk \& Serlin, 1992) that calculates the effects without assumptions regarding homogeneity of variance and population distribution. Separate mean and median effect sizes are reported for each setting (home and school). Computations required computing the difference in phase means (baseline and treatment) within a case and dividing it by the standard deviation of baseline, thereby producing an index of treatment effects. According to Cohen (1992), an effect size of 0.2 is considered small, 0.5 is medium, and 0.8 or greater is large.

To examine the effectiveness of $\mathrm{CBC}$ to strengthen the parent and teacher relationship, paired sample $t$ tests were utilized. This approach employs a comparison between means on two variables for a single group. Paired sample $t$ tests were used 
to analyze changes in ratings on Joining, Communication to Others, and Total Relationship scores (Vickers \& Minke, 1995) for both parents and teachers as a function of CBC.

Descriptive analysis was used to determine perceptions of goal attainment, acceptability of CBC services, and satisfaction with CBC consultants. Perceptions and attitudes surrounding the parent-teacher relationship were also evaluated descriptively. Specifically, parents' and teachers' perceptions of each other's competence as well as their overall perception of their relationship were explored.

\section{RESULTS}

\section{Behavioral Outcomes}

Mean and median effect sizes for behavioral outcomes in home and school settings are presented in Table 3. Across participants and settings, the mean and median effect size for behavioral outcomes was 1.09. The average effect size of all behavioral outcomes in the home setting was $1.01(S D=1.78)$; the median was 0.97. Similarly, the average effect size for all behavioral outcomes in the school setting was $1.15(S D=1.44)$; the median was 1.13 . This suggests generally good effects associated with the CBC-based treatments, with average case outcomes approximately 1 standard deviation above what could be expected based on baseline performance. Findings were generally consistent across settings.

\section{Relationship Outcomes}

Changes in the relationship between parents and teachers as a function of their involvement in CBC were assessed with the PTRS (Vickers \& Minke, 1995). Results are presented in Table 4. Paired sample $t$ tests yielded a significant change in par-

TABLE 3

Mean and Median Effect Sizes by Setting

\begin{tabular}{lcc}
\hline Variable & Home & School \\
\hline$n$ & 29 & 46 \\
Mean ES & 1.01 & 1.15 \\
Median ES & 0.97 & 1.13 \\
SD & 1.78 & 1.44 \\
Min & -4.29 & -1.61 \\
Max & 4.71 & 7.38 \\
\hline
\end{tabular}

Note. $\quad \mathrm{ES}=$ average effect size at home or school; $\mathrm{min}=$ minimum effect size value at home or school; $\max =$ maximum effect size value at home or school. 
TABLE 4

Mean Parent-Teacher Relationship Scale Ratings and Significance Between Pre- and Post-CBC Scores for Parents and Teachers

\begin{tabular}{|c|c|c|c|c|c|c|}
\hline \multirow[b]{2}{*}{ Participant } & \multicolumn{2}{|c|}{ Joining } & \multicolumn{2}{|c|}{$\begin{array}{c}\text { Communication } \\
\text { to Others }\end{array}$} & \multicolumn{2}{|c|}{ Total } \\
\hline & Pre & Post & Pre & Post & Pre & Post \\
\hline \multicolumn{7}{|l|}{ Parent } \\
\hline$M$ & 4.65 & 4.76 & 3.90 & $4.42^{\mathrm{a}}$ & 4.50 & $4.70^{\mathrm{a}}$ \\
\hline$S D$ & 0.33 & 0.26 & 1.02 & 0.68 & 0.43 & 0.29 \\
\hline$n$ & 23 & & 23 & & 23 & \\
\hline \multicolumn{7}{|l|}{ Teacher } \\
\hline$M$ & 4.14 & 4.17 & 3.96 & 4.05 & 4.09 & 4.15 \\
\hline$S D$ & 0.67 & 0.76 & 0.73 & 0.62 & 0.65 & 0.66 \\
\hline$n$ & 28 & & 27 & & 28 & \\
\hline
\end{tabular}

Note. $\quad \mathrm{CBC}=$ conjoint behavioral consultation. All ratings reflect mean item responses on a 5 -point Likert-type scale, with high scores reflecting positive responses.

aSignificant increase from pre- to posttest at the $p<.01$ level.

ents' ratings on the Communication to Others factor and for the total relationship score following CBC (both $p$ s <.01). Parents' ratings on the Joining factor approached significance following CBC $(p=.07)$. There were no significant differences in teacher ratings on any factors or the total relationship score as a result of their involvement in $\mathrm{CBC}$.

\section{Social Validity}

Social validity measures assessed the clinical meaningfulness of outcomes. Assessment of parents' and teachers' subjective evaluations of goal attainment, acceptability and satisfaction with consultation services, and perceptions regarding the parent-teacher relationship were included. Parents' and teachers' perceptions regarding the effectiveness of $\mathrm{CBC}$ were rated on the BIRS Effectiveness factor. Parents tended to view the process as slightly more effective than did teachers. Teachers' ratings of the effectiveness of the CBC intervention at school yielded an average of 4.38 out of a possible score of $6(S D=1.31)$, whereas parents' mean item ratings for home effects were slightly higher, with an average of $4.62(S D=$ 0.78). Similarly, parents' ratings of attainment of goals at home on the GAS (Kiresuk et al., 1994) yielded an average of 4.55 out of a possible score of 5 (where $5=$ goal fully met). Teachers' ratings were slightly lower, with an average of 4.33 for goal attainment at school.

Ratings on the Acceptability factor of the BIRS (Von Brock \& Elliott, 1987) revealed that $\mathrm{CBC}$ was highly acceptable to parents and teachers. Teachers' mean item ratings on the Acceptability factor averaged 5.39 out of a possible 6. Simi- 
larly, parents' mean item ratings were 5.41. Parents and teachers also reported high levels of satisfaction with the CBC consultant and consultation process. Specifically, out of a possible score of 7, parents' ratings of satisfaction as measured on the CEF averaged $6.40(S D=0.55)$, and teachers' ratings averaged $6.37(S D=$ $0.68)$.

\section{DISCUSSION}

The early childhood intervention literature emphasizes the need for cross-system partnerships and collaboration in the education and care of young children. Ecological perspectives stress the importance of relationships between child characteristics and home, school, and family contexts (Rimm-Kaufman \& Pianta, 2000). As such, models of intervention that promote identification of child needs within the natural and mutually interdependent contexts of home and school are desirable. Likewise, promoting assets within the child and strengthening the environments within which the child functions are exemplars for early childhood practice.

In this study, CBC was explored as a mechanism for advancing an ecological approach to early intervention. The specific purposes of the study were to identify the effects of CBC on young children's behaviors across home and school settings; determine parents' and teachers' perceptions of their relationship with one another as a function of $\mathrm{CBC}$; and assess the social validity of the model in terms of its acceptability and perceived effectiveness. Results suggested that interventions implemented in the context of CBC were effective at addressing behavioral, academic, and social-emotional concerns shared by parents and teachers. Parents reported significant changes in their perceptions of communication with their child's educator after completing CBC, and both parents and teachers reported high levels of acceptability, satisfaction, and goal attainment.

Optimal preschool experiences are facilitated (or hindered) by the degree of parent involvement in supporting explicitly educational tasks in the home and in coordinating the nature and structure of these tasks with the preschool context. One of the novel features of the CBC intervention strategy is that parents are engaged in a process that fosters integrated and coherent opportunities for learning within and across multiple contexts. The importance of parental participation and engagement in their child's educational experiences in the elementary years is unequivocal (Christenson \& Sheridan, 2001). However, this is among one of the first studies investigating an intervention model for strengthening partnerships for young children in early childhood settings.

$\mathrm{CBC}$ is designed to facilitate an active role for parents in increasing the consistency and coherence of educational supports across home and school contexts. This study evaluated the effectiveness of CBC and provided valuable information to promote the design of collaborative early childhood interventions. Our concep- 
tualization of collaboration includes the ability of parents and teachers to align developmental and educational goals and activities across home and school contexts. Greater continuity between the values of, and supports for, specific cognitive, socioemotional, and behavioral skills and competencies across home and school environments can be expected to facilitate children's development in these domains. Collaborative goal setting, decision making, and problem solving related to both family- and teacher-identified concerns are among the key objectives. Thus, our model has been designed specifically to structure opportunities for parents and their child's teacher to communicate and come together around shared goals, plans, and experiences for the child.

In addition to addressing shared concerns related to a child's functioning, CBC promotes connected and supportive relationships early in a child's academic experience. Constructive relationships between parents and teachers represent critical support structures for children (Pianta \& Walsh, 1996); however, little intervention research has investigated effective means of strengthening these connections. We explored $\mathrm{CBC}$ as a means for enhancing parent-teacher relationships and found partial support for its success in this capacity.

Results of the study suggest that parents perceived their communication and overall relationships with their child's teacher more favorably after $\mathrm{CBC}$; however, teachers did not report similar findings. The significant change in parents' perceptions of communication with their child's teacher is noteworthy. Given that the direction of the change was positive, it is possible that parents felt as though their ability to communicate with their child's teacher was improved as a function of the CBC experience. Weiss and Edwards (1992) suggested that communications in support of consistent themes are essential. Among the important themes are a desire to develop a working partnership with families, the crucial nature of family input and involvement for children's progress, and the importance of working together to identify a mutually advantageous solution in light of problems (Weiss \& Edwards, 1992). The structure and function of CBC allowed parents and teachers to engage in frequent communication around a common concern and shared goal. It is possible that the relational context established by consultants in CBC provided an avenue for parents to communicate openly with their child's teacher and, ideally, feel more comfortable in that role. However, the degree to which CBC may have fostered experiences of trust, comfort, and success in communication efforts is unknown. These and other intra- and interpersonal dynamics of interactions within CBC are fruitful areas for research.

Interestingly, the same change was not noted in terms of teachers' perceptions of communications to parents. That is, teachers' ratings of communication were not significantly changed as a function of their involvement in $\mathrm{CBC}$. Prior to $\mathrm{CBC}$, teachers had already reported high levels of communication (close to 4 on a 5-point Likert-type scale), and this was improved slightly following CBC. It may be that teachers' perceptions of communicating concerns and goals with parents are al- 
ready within their purview, and thus they do not experience the structured problem-solving meetings as greatly enhancing this process. For parents, however, mechanisms for expressing concerns and opinions may be less common, with the meetings providing a unique and important opportunity to do so.

Neither parents nor teachers reported significant change in joining with the other as assessed on the PTRS. Although parents' reports on this factor approached significance $(p=.07)$, and the total relationship scale documented a significant change $(p<.01)$, there is inconclusive evidence about the degree to which parents felt they joined more effectively with this sample of teachers. Parents' scores on this factor were already very high $(M=4.65$, with a relatively small standard deviation of 0.33 ) at preconsultation, with possible ceiling effects in place. Teachers' preconsultation scores, however, were lower $(M=4.14)$, representing room for improvement. It is unclear why CBC was unsuccessful in raising teachers' perceptions of joining with parents, unless they already believed that optimal levels existed. The degree to which $\mathrm{CBC}$ can be used to enhance this important relationship feature is open for additional research.

Consistent with previous research (Colton \& Sheridan, 1998; Galloway \& Sheridan, 1994; Sheridan, 1997; Sheridan et al., 2001), social validity of CBC for this sample was high, suggesting its appropriateness within early childhood settings. In various measures of social validity, assessing constructs of acceptability, perceived effectiveness, and goal attainment (Eckert \& Hintze, 2000), both parents and teachers reported generally high levels of agreement. This was particularly evident on measures of acceptability of CBC services (as assessed with the BIRS), satisfaction with the consultant (as assessed with the CEF), and goal attainment (as assessed via Goal Attainment Scaling). Given their high ratings of acceptability and the perceived relationship between acceptability and use of interventions (Witt, Elliott, \& Martens, 1984), it can be expected that parents and teachers may be likely to sustain joint interventions including joint problem solving and intervention delivery in the future. Although their perceptions of specific aspects of the process (e.g., data collection, plan development) are unknown, items endorsed most highly by parents and teachers on the BIRS suggested that in general, the process was very acceptable (e.g., "This was an acceptable model of consultation for [my child's] identified problem;" "This model of consultation was a good way to handle [my child's] identified behavior;" "Most teachers would find this model of consultation appropriate for problems in addition to the one addressed ... for a variety of students"). Interestingly, acceptability and satisfaction remained high despite relatively lower levels of perceived effectiveness. It appears that parents and teachers viewed some aspects of $\mathrm{CBC}$ as particularly desirable despite variable perceptions of efficacy.

The measurement of perceived effectiveness as a social validity construct is interesting, as it routinely suggests less favorable outcomes than either behavioral effect sizes or ratings of goal attainment (Sheridan, Clarke, \& Burt, in press). Indeed, 
given that the latter measures yielded rather robust findings, it is possible that the BIRS Effectiveness factor assessed perceptions of change that were nonspecific to the target behaviors addressed in the CBC situation. That is, the BIRS Effectiveness factor may assess changes in behaviors that are more global in nature, whereas the other outcome measures assess change more specific to the focus (i.e., targets) of CBC. Although children demonstrated improvements in the targeted areas of concern and parents and teachers perceived positive change, the outcomes may be considered limited. Means for generalizing positive effects to other behaviors or concerns are clearly in need of identification and study.

This study was the first to examine CBC with an early childhood sample and should be considered exploratory in nature. Although some promising findings were suggested, several limitations urge caution in interpretation of the findings. First, participants in the study were referred for CBC services over the course of several years. Random assignment to conditions was not possible, resulting in a quasi-experimental approach to the study. In light of this limitation, various steps were taken to minimize threats to internal validity and strengthen the inferences that could be drawn from the small- $n$ method of case analysis. These included (a) the use of standardized interview forms, (b) continuous data collection, (c) verification of treatment integrity, (d) assessment of social validity, and (e) replication of CBC procedures across participants (Galloway \& Sheridan, 1994; Kratochwill, 1985).

Second, the observational data reported were recorded by parents and teachers rather than independent observers trained in behavioral assessment methodology, and their accuracy cannot be determined unequivocally. Consistent with best practices in single-subject design, clear operationalization of target concerns, parent and teacher training in data collection, graphing of results, and debriefing were used to maximize reliability of the behavioral data (Galloway \& Sheridan, 1994; Sheridan, Erchul et al., 2004). Parents and teachers contributed in the design of the observational systems used in their respective setting, recorded their observations on standard record forms, and reported on feasibility and challenges associated with data collection. Time was spent in CBC interviews reviewing the procedures, asking and answering questions, and discussing the data to maximize their reliability. Although the reliability of the behavioral data is not known, they are considered very authentic in that they were collected in actual casework in home and school settings by natural treatment agents. It is possible that the ownership with which parents and teachers approached the task of data collection, their contribution to the establishment of meaningful and practical procedures, and their follow-through may help sustain objective and systematic approaches to problem solving in the future.

A third limitation concerns the relatively small sample size, coupled with variability in the effect sizes yielded by cases. Standard deviations for both home and school behaviors were greater than 1 standard deviation, suggesting that the 
CBC-based interventions were responded to inconsistently across participants. Future research is sorely needed that determines the contexts and conditions under which CBC is effective in addressing targeted concerns. This might include the investigation of characteristics of children, behaviors, families, classrooms, and a host of other possible ecological, internal, and interpersonal variables and their interactions that may affect outcomes in direct and indirect ways.

Fourth, there was no direct measure of the integrity with which parents and teachers implemented interventions. Again, although a great deal of time was spent during the meetings discussing plans, procedures, strategies, and tactics, actual implementation parameters are unknown. Plans were recorded on treatment plan worksheets, which also included a self-report matrix allowing parents and teachers to record completion of plan steps. Although this is not a direct and objective measure, it has been offered as one means of assessing fidelity (Gresham, 1989). The degree to which plan elements and treatment outcomes are related is still in need of investigation in both consultation and intervention research.

Finally, the application of this model in early intervention settings, schools, and communities with unique demographic or familial characteristics is unknown. For example, the effects of $\mathrm{CBC}$ in schools with high percentages of families living in poverty, speaking diverse languages, or moving into and out of the school community, have not been studied specifically. Characteristics such as these may present challenging resource demands for schools and families (e.g., staff, time, materials), creating difficulties in the systematic delivery of structured consultation services with family members. As previously indicated, children from various ethnic and socioeconomic backgrounds have been involved in $\mathrm{CBC}$ and have experienced success. CBC requires the active participation and willingness of teachers regardless of context; the intervention is not a blanket approach that can be applied in every situation. Recent research (Sheridan, Eagle, \& Doll, 2006) found that CBC is highly effective for children from diverse backgrounds (including ethnicity, language spoken in the home, and socioeconomic status, to name a few). Social validity measures also yielded very favorable results, suggesting that participants (teachers and family members of diverse children) found the procedures to be positive. Nevertheless, the degree to which the current findings can be generalized across diverse early education settings is unclear.

In sum, the key elements of successful early intervention-opportunities for building cross-system partnerships, collaboration, and support-have been identified in previous research. CBC provides a structured, data-based model of service delivery that addresses these factors using an ecological-dynamic, family-centered approach to problem solving. This study provides promising results for the utilization of CBC with early childhood populations and their teachers and parents in addressing academic, behavioral, and social concerns. It also suggests that CBC is an acceptable decision-making method that allows parents and teachers to communicate and collaborate on behalf of the child. Although these findings are exploratory, 
they provide the impetus for more research related to the use of CBC as a tool for preparing young children, as well as parents and teachers, for academic success.

\section{ACKNOWLEDGMENTS}

The study presented herein was supported by grants provided by the U.S. Department of Education, Office of Special Education Programs, and the National Institute of Child Health and Human Development, Office of Special Education Programs, Administration for Children, Youth and Families. The opinions expressed herein belong to us and do not represent those of the funding agency. We would like to extend gratitude to the several children, families, teachers, and consultants who participated in the project over the course of several years. Carolyn Edwards acknowledges the support of the University of Nebraska Institute for Agricultural and Natural Resources, Journal Series 15109.

\section{REFERENCES}

Alexander, K. L., \& Entwisle, D. R. (1988). Achievement in the first 2 years of school: Patterns and processes. Monographs of the Society for Research in Child Development, 53(2, Serial No. 218).

Bradley, R. H., Caldwell, B. M., \& Rock, S. L. (1988). Home environment and school performance: A ten-year follow-up and examination of three models of environmental action. Child Development, 59, 852-867.

Bronfenbrenner, U. (1977). Toward an experimental ecology of human development. American Psychologist, 32, 513-529.

Busk, P. L., \& Serlin, R. C. (1992). Meta-analysis for single-case research. In T. R. Kratochwill \& J. R. Levin (Eds.), Single-case research design and analysis: Applications in psychology and education (pp. 187-212.). Hillsdale, NJ: Lawrence Erlbaum Associates, Inc.

Cardillo, J. E., \& Smith, A. (1994). Psychometric issues. In T. J. Kiresuk, A. Smith, \& J. E. Cardillo (Eds.), Goal Attainment Scaling: Applications, theory, and measurement (pp. 173-241). Hillsdale, NJ: Lawrence Erlbaum Associates, Inc.

Christenson, S. L. (2000). Families and schools: Rights, responsibilities, resources, and relationship. In R. C. Pianta \& M. J. Cox (Eds.), The transition to kindergarten (pp. 143-177). Baltimore: Brookes.

Christenson, S. L., \& Sheridan, S. M. (2001). Schools and families: Creating essential connections for learning. New York: Guilford.

Cohen, J. (1992). A power primer. Psychological Bulletin, 112, 155-159.

Colton, D., \& Sheridan, S. M. (1998). Conjoint behavioral consultation and social skills training: Enhancing the play behavior of boys with attention deficit-hyperactivity disorder. Journal of Educational and Psychological Consultation, 9, 3-28.

Conoley, J. C. (1987). Schools and families: Theoretical and practical bridges. Professional School Psychology, 2, 191-203.

Dunst, C. J., \& Trivette, C. M. (1987). Enabling and empowering families: Conceptual and intervention issues. School Psychology Review, 16, 443-456. 
Dunst, C. J., Trivette, C. M., \& Deal, A. G. (1994). Enabling and empowering families. In C. J. Dunst, C. M. Trivette, \& A. G. Deal (Eds.), Supporting and strengthening families (pp. 1-22). Cambridge, MA: Brookline Books.

Early, D. M., Pianta, R. C., Taylor, L. C., \& Cox, M. J. (2001). Transition practices: Findings from a national survey of kindergarten teachers. Early Childhood Education Journal, 28, 199-206.

Eayrs, C. B., \& Jones, R. P. (1992). Methodological issues and future directions in the evaluation of early intervention programmes. Child Care, Health and Development, 18, 15-28.

Eckert, T. L., \& Hintze, J. M. (2000). Behavioral conceptions and applications of acceptability: Issues related to service delivery and research methodology. School Psychology Quarterly, 15, 123-148.

Elliott, S. N., \& Von Brock Treuting, M. (1991). The Behavior Intervention Rating Scale: Development and validation of a pretreatment acceptability and effectiveness measure. Journal of School Psychology, 29, 43-51.

Entwisle, D. R., Alexander, K. L., Cadigan, D., \& Pallas, A. M. (1986). The schooling process in first grade: Two samples a decade apart. American Educational Research Journal, 24, 587-613.

Epstein, J. (2001). School, family, and community partnerships. Boulder, CO: Westview.

Erchul, W. P. (1987). A relational communication analysis of control in school consultation. Professional School Psychology, 2, 113-124.

Freer, P., \& Watson, T. S. (1999). A comparison of parent and teacher acceptability ratings of behavior and conjoint behavioral consultation. School Psychology Review, 28, 672-684.

Galloway, J., \& Sheridan, S. M. (1994). Implementing scientific practices through case studies: Examples using home-school interventions and consultation. Journal of School Psychology, 32, 385-413.

Gresham, F. M. (1989). Assessment of treatment integrity in school consultation and prereferral intervention. School Psychology Review, 18, 37-50.

Grolnick, W. S., \& Slowiaczek, M. L. (1994). Parents' involvement in children's schooling: A multidimensional conceptualization and motivational model. Child Development, 65, 237-252.

Hansen, D. A. (1986). Family-school articulations: The effects of interaction rule mismatch. American Educational Research Journal, 23, 643-659.

Haynes, N. M., Comer, J. P., \& Hamilton-Lee, H. M. (1989). School climate enhancement through parental involvement. Journal of School Psychology, 27, 87-90.

Henderson, A. T., \& Mapp, K. L. (2002). A new wave of evidence: The impact of school, family, and community connections on student achievement. Austin, TX: Southwest Educational Development Laboratory.

Hill, N. E. (2001). Parenting and academic socialization as they relate to school readiness: The roles of ethnicity and family income. Journal of Educational Psychology, 93, 686-697.

Hoover-Dempsey, K. V., \& Sandler, H. M. (1997). Why do parents become involved in their children's education? Review of Educational Research, 67, 3-42.

Husen, T. (1969). Talent, opportunity, and career. Stockholm, Sweden: Almqvist \& Wiksell.

Jacobs, S., \& Cytrynbaum, S. (1977). The goal attainment scale: A test of its use on an inpatient crisis intervention unit. Goal Attainment Review, 3, 77-98.

Johnson, S. M., \& Greenberg, L. S. (1985). Differential effects of experiential and problem-solving interventions in resolving marital conflict. Journal of Consulting and Clinical Psychology, 53, 175-184.

Kaplan, J. M., \& Smith, W. G. (1977). The use of attainment scaling in the evaluation of a regional mental health program. Community Mental Health Journal, 13, 188-193.

Kiresuk, T. J., Smith, A., \& Cardillo, J. E. (Eds.). (1994). Goal Attainment Scaling: Applications, theory, and measurement. Hillsdale, NJ: Lawrence Erlbaum Associates, Inc.

Kratochwill, T. R. (1985). Case study research in school psychology. School Psychology Review, 14, 204-215. 
Kratochwill, T. R., Sheridan, S. M., Carrington Rotto, P. J., \& Salmon, D. E. (1992). Preparation of school psychologists to serve as consultants for teachers of emotionally disturbed children. School Psychology Review, 20, 530-550.

Ladd, G. W., \& Price, J. M. (1987). Predicting children's social and school adjustment following the transition from preschool to kindergarten. Child Development, 58, 1168-1189.

Lee, S. (1993). Family structure effects on student outcomes. In B. Schneider \& J. S. Coleman (Eds.), Parents, their children, and schools (pp. 43-75). Boulder, CO: Westview.

Masten, A. S., \& Coatsworth, J. D. (1998). The development of competence in favorable and unfavorable environments: Lessons from research on successful children. American Psychologist, 53, 205-220.

Noell, G. H. (in press). Research examining the relationships among consultation process, treatment integrity, and outcomes. In W. P. Erchul \& S. M. Sheridan (Eds.), Handbook of research in school consultation: Empirical foundations for the field. Mahwah, NJ: Lawrence Erlbaum Associates, Inc.

Phelan, P., Davidson, A. L., \& Yu, H. C. (1998). Adolescents' worlds: Negotiating family, peers, and school. New York: Teachers College Press.

Pianta, R. C., Kraft-Sayre, M., Rimm-Kaufman, S., Gercke, N., \& Higgins, T. (2001). Collaboration in building partnerships between families and schools: The National Center for Early Development and Learning's kindergarten transition intervention. Early Childhood Research Quarterly, 16, 117-132.

Pianta, R. C., \& Walsh, D. J. (1996). High-risk children in schools: Constructing sustaining relationships. New York: Routledge.

Rafaelle, L. M., \& Knoff, H. M. (1999). Improving home-school collaboration with disadvantaged families: Organizational principles, perspectives, and approaches. School Psychology Review, 28, 448-466.

Ramey, S. L. (1999). Head start and preschool education: Toward continued improvement. American Psychologist, 54, 344-346.

Reynolds, A. J. (1991). Early schooling of children at risk. American Educational Research Journal, $28,392-422$.

Reynolds, A. J., Weissberg, R. P., \& Kasprow, W. (1992). Prediction of early social and academic adjustment of children from the inner city. American Journal of Community Psychology, 20, 599-624.

Rimm-Kaufman, S. E., \& Pianta, R. C. (2000). An ecological perspective on the transition to kindergarten: A theoretical framework to guide empirical research. Journal of Applied Developmental Psychology, 21, 491-511.

Sheridan, S. M. (1992). Consultant and client outcomes of competency-based behavioral consultation training. School Psychology Quarterly, 7, 245-270.

Sheridan, S. M. (1997). Conceptual and empirical bases of conjoint behavioral consultation. School Psychology Quarterly, 12, 119-133.

Sheridan, S. M., Clarke, B. L., \& Burt, J. D. (in press). Conjoint behavioral consultation: What do we know and what do we need to know? In W. P. Erchul \& S. M. Sheridan (Eds.), Handbook of research in school consultation: Empirical foundations for the field. Mahwah, NJ: Lawrence Erlbaum Associates, Inc.

Sheridan, S. M., Eagle, J. W., Cowan, R. J., \& Mickelson, W. (2001). The effects of conjoint behavioral consultation: Results of a 4-year investigation. Journal of School Psychology, 39, 361-385.

Sheridan, S. M., Eagle, J. W., \& Doll, B. (2006). An examination of the efficacy of conjoint behavioral consultation with diverse clients. School Psychology Quarterly, 21, 396-417.

Sheridan, S. M., \& Erchul, W. P. (1995). Consultee final perceptions form. Unpublished scale. Salt Lake City, University of Utah and Raleigh, North Carolina State University.

Sheridan, S. M., Erchul, W. P., Brown, M. S., Dowd, S. E., Warnes, E. D., Marti, D. C., et al. (2004). Perceptions of helpfulness in conjoint behavioral consultation: Congruence and agreement between teachers and parents. School Psychology Quarterly, 41, 7-17.

Sheridan, S. M., \& Kratochwill, T. R. (1992). Behavioral parent-teacher consultation: Conceptual and research considerations. Journal of School Psychology, 30, 117-139. 
Sheridan, S. M., Kratochwill, T. R., \& Bergan, J. R. (1996). Conjoint behavioral consultation: A procedural manual. New York: Plenum.

Sheridan, S. M., Kratochwill, T. R., \& Elliott, S. N. (1990). Behavioral consultation with parents and teachers: Delivering treatment for socially withdrawn children at home and school. School Psychology Review, 19, 33-52.

Sheridan, S. M., Salmon, D., Kratochwill, T. R., \& Carrington Rotto, P. J. (1992). A conceptual model for the expansion of behavioral consultation training. Journal of Educational and Psychological Consultation, 3, 193-218.

Sheridan, S. M., \& Steck, M. (1995). Acceptability of conjoint behavioral consultation: A national survey of school psychologists. School Psychology Review, 24, 633-647.

Sheridan, S. M., Warnes, E. D., Schemm, A. V., Cowan, R. J., \& Clarke, B. L. (2004). Family centered positive psychology: Focusing on strengths to build student success. Psychology in the Schools, 41, 7-17.

Siu-Chu, H. O., \& Willms, J. D. (1996). Effects of parental involvement on eighth grade achievement. Sociology of Education, 69, 126-141.

Stevenson, D. L., \& Baker, D. P. (1987). The family-school relation and the child's school performance. Child Development, 58, 1348-1357.

Vickers, H. S., \& Minke, K. M. (1995). Exploring parent-teacher relationships: Joining and communication to others. School Psychology Quarterly, 10, 133-150.

Von Brock, M. B., \& Elliott, S. N. (1987). Influence of treatment effectiveness information on the acceptability of classroom interventions. Journal of School Psychology, 25, 131-144.

Walberg, H. (1984). Families as partners in educational productivity. Phi Delta Kappan, 65, 397-400.

Weiner, R., Sheridan, S. M., \& Jenson, W. R. (1998). Effects of conjoint behavioral consultation and a structured homework program on math completion and accuracy in junior high students. School Psychology Quarterly, 13, 281-309.

Weiss, H. M., \& Edwards, M. E. (1992). The family-school collaboration project: Systemic interventions for school improvement. In S. L. Christenson \& J. C. Conoley (Eds.), Home-school collaboration: Enhancing children's academic and social competence (pp. 215-243). Silver Spring, MD: National Association of School Psychologists.

Weissberg, R. P., \& Greenberg, M. T. (1998). School and community competence-enhancement and prevention programs. In W. Damon (Series Ed.) \& I. E. Sigel \& K. A. Renninger (Vol. Eds.), Handbook of child psychology: Vol. 4. Child psychology in practice (5th ed., pp. 877-954). New York: Wiley.

Witt, J., Elliott, S. N., \& Martens, B. K. (1984). Acceptability of behavioral interventions used in classrooms: The influence of amount of teacher time, severity of behavior problem, and type of intervention. Behavioral Disorders, 9, 95-104.

Woodward, C. A., Santa-Barbara, J., Levin, S., \& Epstein, N. (1978). The role of Goal Attainment Scaling in evaluating family therapy outcome. American Journal of Orthopsychiatry, 48, 464-476.

Zellman, G. L., \& Waterman, J. M. (1998). Understanding the impact of parent school involvement on children's educational outcomes. Journal of Educational Research, 91, 370-380. 